Provided for non-commercial research and education use. Not for reproduction, distribution or commercial use.

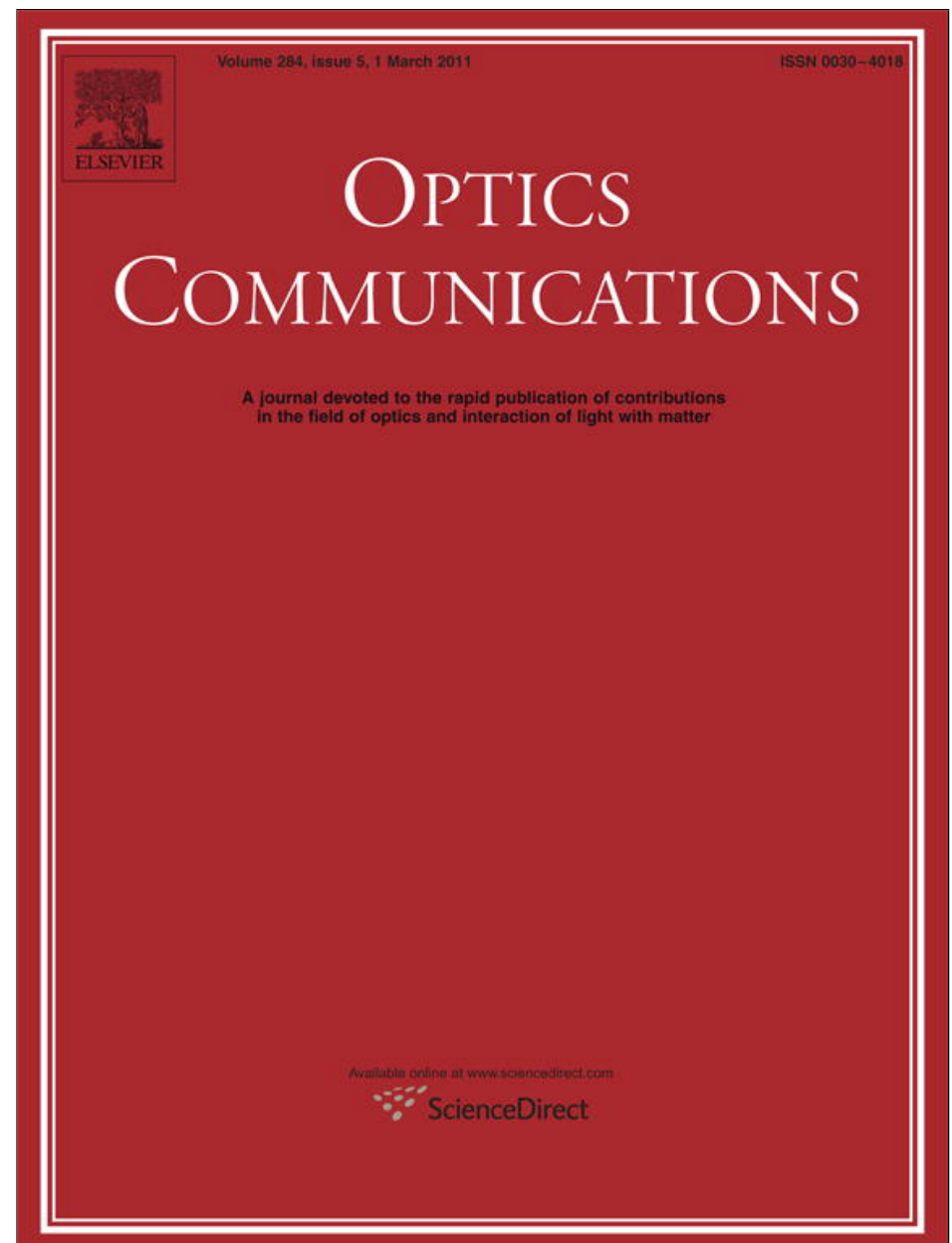

This article appeared in a journal published by Elsevier. The attached copy is furnished to the author for internal non-commercial research and education use, including for instruction at the authors institution and sharing with colleagues.

Other uses, including reproduction and distribution, or selling or licensing copies, or posting to personal, institutional or third party websites are prohibited.

In most cases authors are permitted to post their version of the article (e.g. in Word or Tex form) to their personal website or institutional repository. Authors requiring further information regarding Elsevier's archiving and manuscript policies are encouraged to visit:

http://www.elsevier.com/copyright 


\title{
First-time lidar measurement of water vapor flux in a volcanic plume
}

\author{
Luca Fiorani $^{\mathrm{a}, *}$, Francesco Colao $^{\mathrm{a}}$, Antonio Palucci $^{\mathrm{a}}$, Davod Poreh ${ }^{\mathrm{b}}$, Alessandro Aiuppa ${ }^{\mathrm{c}, \mathrm{d}}$, Gaetano Giudice ${ }^{\mathrm{d}}$ \\ a UTAPRAD-DIM, ENEA, Via Enrico Fermi 45, 00044 Frascati, Italy \\ b ENEA guest with ICTP fellowship, ENEA, Via Enrico Fermi 45, 00044 Frascati, Italy \\ c CFTA, Università di Palermo, Via Archirafi 36, 90123 Palermo, Italy \\ d Istituto Nazionale di Geofisica e Vulcanologia, Sezione di Palermo, Via La Malfa 143, 90146 Palermo, Italy
}

\section{A R T I C L E I N F O}

\section{Article history:}

Received 17 June 2010

Received in revised form 15 September 2010

Accepted 24 October 2010

\section{Keywords:}

Lidar

DIAL

Correlation technique

Water vapor

Wind speed

Volcanic plume

\begin{abstract}
A B S T R A C T
The $\mathrm{CO}_{2}$ laser-based lidar ATLAS has been used to study the Stromboli volcano plume. ATLAS measured water vapor concentration in cross-sections of the plume and wind speed at the crater. Water vapor concentration and wind speed were retrieved by differential absorption lidar and correlation technique, respectively. Lidar returns were obtained up to a range of $3 \mathrm{~km}$. The spatial resolution was $15 \mathrm{~m}$ and the temporal resolution was $20 \mathrm{~s}$. By combining these measurements, the water vapor flux in the Stromboli volcano plume was found. To our knowledge, it is the first time that lidar retrieves water vapor concentrations in a volcanic plume.
\end{abstract}

(C) 2010 Elsevier B.V. All rights reserved.

\section{Introduction}

Stromboli is a small island in the Tyrrhenian Sea, off the north coast of Sicily, hosting one of the most active volcanoes in Italy. The most recent volcano eruptions (on December 2002-July 2003 and February-April 2007) generated a tsunami and two paroxysmal explosions, which caused serious damages to the Stromboli villages and created strong alarm. In order to assess the potential volcanic hazard and the risks associated with the population, the Italian Civil Protection National Service (DPC) supports continuous monitoring of the volcano, and eventually restricts the access to dangerous zones. Researchers of the Italian National Institute of Geophysics and Volcanology (INGV) maintain this activity investigating, among others, the volcanic emissions and relating variations in gaseous concentrations to eruptive events [1]. In this framework, the Diagnostics and Metrology Laboratory (UTAPRAD-DIM) of the Italian National Agency for New Technologies, Energy and Sustainable Economic Development (ENEA) carried out remote sensing of water vapor in the volcano plume with the Agile Tuner Lidar [2] for Atmospheric Sensing (ATLAS) mounted on the Environmental Laboratory (ENVILAB) hosted in a small truck.

\footnotetext{
* Corresponding author.

E-mail address: luca.fiorani@enea.it (L. Fiorani).
}

\section{Instruments and methods}

ATLAS has already been described in a paper reporting on the measurement of Mount Etna plume [3]. Let us simply recall here that it is based on a tunable $\mathrm{CO}_{2}$ laser, a gold coated Newton telescope and a liquid-nitrogen-cooled mercury-cadmium-telluride photodiode. Its main specifications are listed in Table 1 . During the Etna campaign, ATLAS operated only vertically and the plume was too far, thus preventing the detection of water vapor inside it. During summer 2009, ATLAS underwent some major improvements: the laser high voltage circuit was upgraded; the transmitter optics was repolished; the telescope was recoated; a two mirror system, similar to a coelostat, was implemented, in order to scan the whole hemisphere above the horizon. A gain of a factor 3-4 in terms of signal-to-noise ratio can be estimated as a result of these improvements. Eventually, the water vapor flux in the Stromboli volcano plume was measured on 17 September 2009. To our knowledge, it is the first time that the water vapor flux in a volcanic plume is retrieved by lidar, although laser remote sensing has been already applied to sound volcanic particulate in the lower stratosphere [4] and fluxes of aerosol [5] and $\mathrm{SO}_{2}[6]$ in volcanic plumes.

The water vapor concentration in the volcanic plume was measured by differential absorption lidar (DIAL) [2] using the 10R18 $\left(\lambda_{\mathrm{OFF}}\right)$ and 10R20 $\left(\lambda_{\mathrm{ON}}\right)$ lines of the $\mathrm{CO}_{2}$ laser [7].

The wind speed was measured observing by successive lidar echoes the transport of the volcanic aerosol by the surrounding air mass, a method called "correlation technique", pioneered in the seventies [8] and applied in the nineties [9] to retrieve trace gas fluxes. 
Table 1

Main specifications of ATLAS. Note that the laser linewidth is small if compared with the $\mathrm{H}_{2} \mathrm{O}$ absorption linewidth $\left(0.86 \mathrm{~cm}^{-1}\right)$.

\begin{tabular}{lll}
\hline Transmitter & Pulse energy & $\begin{array}{l}850 \mathrm{~mJ} \text { (at the 10R18 and 10R20 } \\
\text { emission lines) }\end{array}$ \\
& Pulse duration & $60 \mathrm{~ns}$ (full width at half maximum) \\
& Repetition rate & $2-20 \mathrm{~Hz}$ \\
& Transmitted wavelength & $9.2-10.8 \mu \mathrm{m}$ \\
& Laser linewidth & $0.13 \mathrm{~cm}^{-1}$ \\
& Beam divergence & $0.7 \mathrm{mrad}$ \\
Receiver & Mirror coating & Au \\
& Diameter & $310 \mathrm{~mm}$ \\
& Focal length & $1.2 \mathrm{~m}$ \\
Detector & Range of overlap & $150 \mathrm{~m}$ (partial), $300 \mathrm{~m}$ (full) \\
& Diameter & $1 \mathrm{~mm}$ \\
& Specific detectivity & $4 \times 10^{10} \mathrm{~cm} \mathrm{~Hz}^{1 / 2} \mathrm{~W}^{-1}$ \\
& Gain & 200 \\
Analog-to-digital & Linear dynamic range & $0.1-1000 \mathrm{mV}$ \\
converter & Bandwidth & $0-10 \mathrm{MHz}^{-1}$ \\
& Sampling rate & $8 \mathrm{bit}$ \\
& & $10 \mathrm{Ms} \mathrm{s}^{-1}$
\end{tabular}

\section{Results and discussion}

ATLAS was located at latitude $38.80074 \mathrm{~N}$ and longitude 15.24064 $\mathrm{E}$ (Fig. 1), i.e. near the harbor and about $2 \mathrm{~km}$ north east from the main crater. The repetition rate was $10 \mathrm{~Hz}$ and 200 lidar returns were averaged, corresponding to a temporal resolution of $20 \mathrm{~s}$. The spatial resolution depends on the sampling rate and is $15 \mathrm{~m}$.

The wind came from south west, blowing the plume south of ATLAS. Consequently, in order to obtain cross-sections of water vapor concentration in the volcanic plume, the lidar was aimed south west with a fixed azimuth angle (Fig. 1) while varying the elevation angle.

During the first scan the azimuth angle (starting from north and rotating clockwise) was $237^{\circ}$, i.e. the laser beam was over the mountain flank between the peak crater and the east coast of Stromboli (Fig. 1). The elevation angles (starting from the horizon and going to the vertical) were from $23^{\circ}$ to $37^{\circ}$ at steps of $2^{\circ}$. The volcanic plume was detected at elevation angles $31^{\circ}$ and $33^{\circ}$. The plume scan was carried out between 12:20 and 12:27 pm (local civil time).

The azimuth angle of the second scan was $192^{\circ}$, i.e. the laser beam was over the sea surface, nearly parallel to the east coast of Stromboli (Fig. 1). The elevation angles were from $5^{\circ}$ to $85^{\circ}$ at steps of $10^{\circ}$. For the elevation angle $75^{\circ}(16: 24 \mathrm{pm})$ the plume signal was particularly evident.

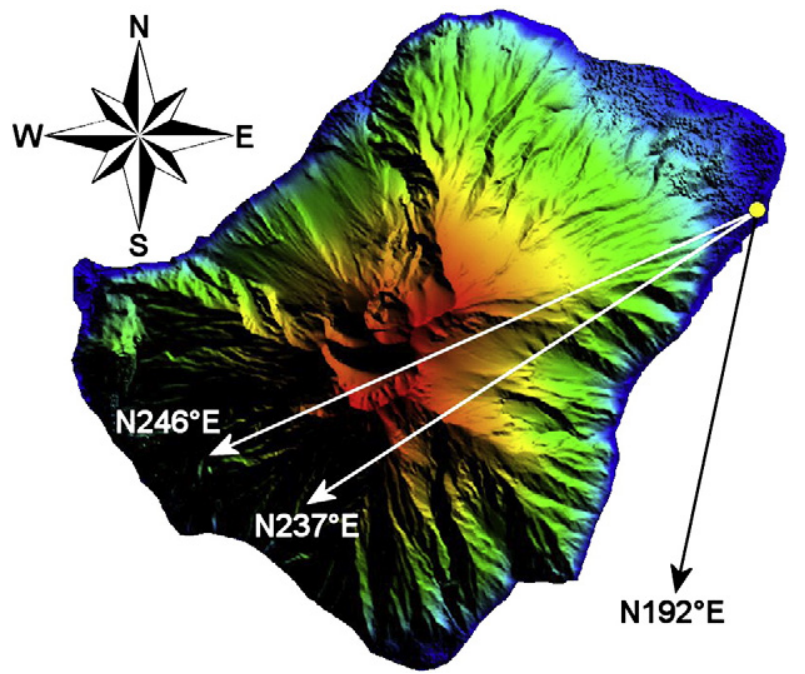

Fig. 1. Location of ATLAS (circle) and directions of the laser beam during the measurements.
The two scans obtained in this way are shown in Fig. 2. Fixing a Cartesian coordinate system with origin in ATLAS, $\mathrm{x}$-axis from west to east, $y$-axis from south to north and z-axis vertical, the water vapor concentration maxima of the two scans occurred at the following points:

$\mathrm{P}_{237}=(-1274 \mathrm{~m},-827 \mathrm{~m}, 863 \mathrm{~m})$,

$P_{192}=(-52 \mathrm{~m},-243 \mathrm{~m}, 927 \mathrm{~m})$.

The unit vector going from $\mathrm{P}_{237}$ to $\mathrm{P}_{192}$ is:

$\mathrm{u}_{\mathrm{w}}=(0.901253,0.430714,0.047201)$

and gives the wind direction. The azimuth angle of the wind direction is $64^{\circ}$. This value is in good agreement with measurements carried out in the time interval of lidar operations with a meteo station mounted on the top of the truck $\left(61^{\circ} \pm 72^{\circ}\right)$.

The cross-sectional areas of the volcanic plume corresponding to the two scans were identified by the points with concentration greater than 10 Torr, the approximate level of water vapor background, i.e. not linked to the Stromboli emission, as it can be inferred from Fig. 2. The concentrations averaged in these cross-sectional areas were:

$\mathrm{C}_{237}=20.3 \pm 4.1$ torr

$\mathrm{C}_{192}=17.3 \pm 2.3$ torr

The concentration error was inferred from the measured signal-tonoise ratio of the lidar signal and is about $10 \%$ at the range where the laser beam intersects the volcanic plume. The measurements of concentration are in good agreement for the two scans. Their average is:

$\mathrm{C}=18.8 \pm 2.4$ Torr $=1.81 \times 10^{-2} \pm 0.23 \times 10^{-2} \mathrm{~kg} \mathrm{~m}^{-3}$.

This value is consistent with simultaneous in-plume measurements carried out in situ (i.e. on the volcano summit, $\sim 150 \mathrm{~m}$ downwind the active open vents) using a near-dispersive infrared (NDIR) spectrometer [13], from which a time-averaged plume $\mathrm{H}_{2} \mathrm{O}$ concentration of $\sim 19$ Torr was derived. $\mathrm{H}_{2} \mathrm{O}$ concentrations in the background atmosphere - measured with the same method averaged at $\sim 14$ Torr on 17 September 2009. The discrepancy between the water vapor natural background measured by lidar and NDIR spectrometer is explained by the different sampling zones: while the lidar scans the atmosphere also far from the volcanic plume, the NDIR spectrometer operates only in proximity of the active open vents, where some water vapor can be transported from the volcanic plume.
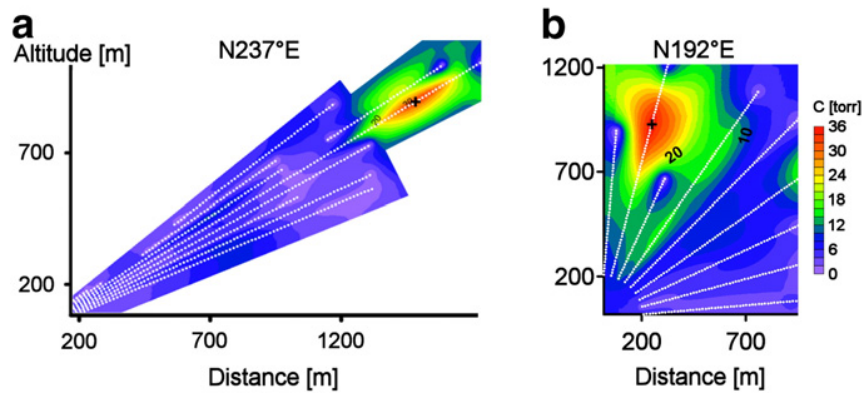

Fig. 2. Water vapor concentration retrieved by ATLAS during two scans at $237^{\circ}$ (a) and $192^{\circ}$ (b) azimuth angles. The white points are the lidar measurements. The black crosses are the points where the water vapor concentration maxima of the two scans occurred, i.e. $\mathrm{P}_{237}$ (a) and $\mathrm{P}_{192}$ (b). 
The wind speed along the laser beam was measured aiming ATLAS to the peak crater (azimuth angle $246^{\circ}$, elevation angle $25^{\circ}$ ): in this way the lidar direction was as much parallel as possible to the wind while still intersecting the volcanic plume (if the beam does not interact with the plume, the correlation technique cannot be applied). The plume was located at the range of 2100-2700 m from ATLAS, as it can be inferred by the extinction coefficient profile (Fig. 3). As already described elsewhere [3], the extinction coefficient was retrieved from the lidar signal with an inversion method [10] derived from the algorithms published by Klett [11] and Fernald [12]. It was assumed that the extinction coefficient was $10^{-5} \mathrm{~m}^{-1}$ at the reference range of $3000 \mathrm{~m}$, according to our previous measurements [3]. Consequently, the correlation function was calculated in the range interval 2100$2700 \mathrm{~m}$ for ten successive lidar profiles (one each $10 \mathrm{~s}$ ), thus observing the displacement of aerosol inhomogeneities for $100 \mathrm{~s}$. An example of correlation function is given in Fig. 3. Ten measurements of this kind were carried between 13:33 and 14:11 pm. Averaging these measurements the wind speed along the laser beam resulted in $3.4 \pm 1.3 \mathrm{~m} \mathrm{~s}^{-1}$. In order to obtain the actual wind speed $\mathrm{w}$, this latter measurement has to be divided by the absolute value of the dot product of $\mathrm{u}_{\mathrm{w}}$ and the unit vector corresponding to the laser beam direction:

$\mathrm{u}_{246}=(-0.827953,-0.368629,0.422618)$,

resulting in:

$\mathrm{w}=3.8 \pm 1.5 \mathrm{~ms}^{-1}$.

This value is in reasonable agreement with the measurements carried out in the time interval of lidar operations with the meteo
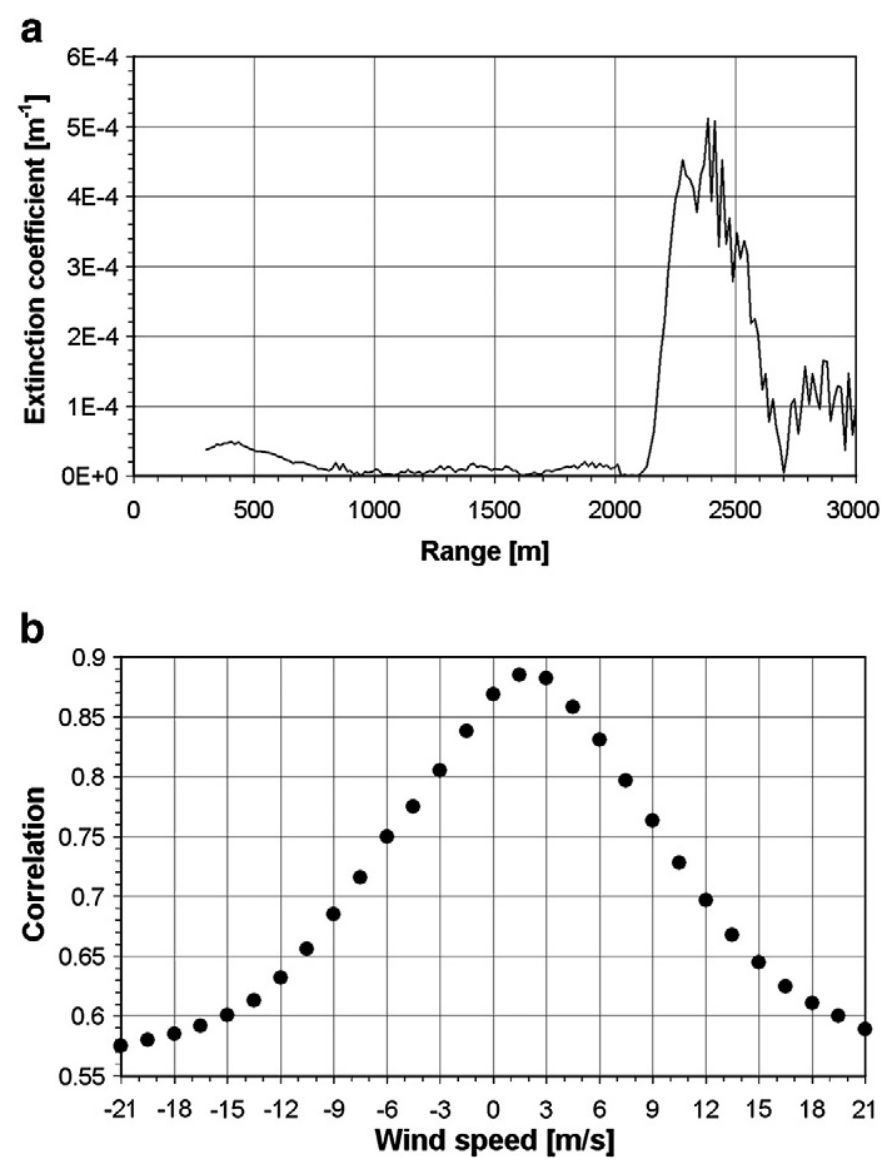

Fig. 3. Extinction coefficient (a) and correlation versus wind speed (b) retrieved at 13:57 pm by ATLAS. station mentioned earlier $\left(8.2 \pm 2.9 \mathrm{~m} \mathrm{~s}^{-1}\right)$. Unfortunately, as already shown in a detailed statistical analysis [9], because of the signal noise contribution to the correlation function, the speed error of the correlation technique is rather large (comparable with the wind speed step, i.e. $1.5 \mathrm{~m} \mathrm{~s}^{-1}$ in our case, as it can be inferred from Fig. 3). Another important source of error is the natural variation of the wind speed and direction during the measurement time that, in our case, is rather long (38 $\mathrm{min}$ ). This natural variation dominates the error of the wind measurements carried out with the meteo station. The fact that the meteo station error $\left(2.9 \mathrm{~m} \mathrm{~s}^{-1}\right)$ is larger than the lidar error $\left(1.5 \mathrm{~m} \mathrm{~s}^{-1}\right)$ is not surprising because the fluctuation of the wind measurements carried out with the meteo station is larger due to its proximity with the ground, where air masses are more affected by eddies and turbulences. Nevertheless, the comparison between meteo station and lidar indicates that the contribution of the natural variation to the wind uncertainty is comparable with the error itself. In conclusion, the speed error and its contributions from signal noise and natural variation are all of the order of $1 \mathrm{~m} \mathrm{~s}^{-1}$ and it is not possible to separate the different contributions.

Although the correlation technique is not very precise, it allows one to gain information on the wind field from lidar returns exactly in the same space zone and time interval where the water vapor concentration is measured. Moreover, it does not require the deployment of any other instrument.

Combining the measurements of average concentrations and wind speed, the following water vapor flux can be calculated:

$\Phi=\mathrm{C} \times \mathrm{w}=0.069 \pm 0.029 \mathrm{~kg} \mathrm{~m}^{-2} \mathrm{~s}^{-1}$.

The contribution to this flux from the volcanic plume can be obtained subtracting the natural background from C, thus giving:

$\Phi_{\mathrm{P}}=0.032 \pm 0.015 \mathrm{~kg} \mathrm{~m}^{-2} \mathrm{~s}^{-1}$,

corresponding to the daily emission rate:

$\mathrm{R}=\Phi_{\mathrm{P}} \times \mathrm{A}=118 \pm 55 \mathrm{~kg} \mathrm{~s}^{-1}=10200 \pm 4800 \mathrm{tday}^{-1}$,

where A, cross-sectional area of the volcanic plume, has been inferred from Fig. 2a, considering the points where the water vapor concentration is larger than 20 Torr.

This value has been compared with the conventional indirect measurement based on the knowledge of both the plume $\mathrm{H}_{2} \mathrm{O} / \mathrm{SO}_{2}$ mass ratio and the $\mathrm{SO}_{2}$ daily emission rate [14]. On 17 September 2009, we estimated:

- an average $\mathrm{H}_{2} \mathrm{O} / \mathrm{SO}_{2}$ mass ratio of $\sim 56$ from MultiGAS, the permanent network of Stromboli [1,13],

- an average $\mathrm{SO}_{2}$ daily emission rate of $\sim 100 \mathrm{t}_{\text {day }}{ }^{-1}$ from FLAME, the scanner network based on differential optical absorption in the ultraviolet [15],

yielding to a water vapor daily emission rate of $5600 \pm 1100$ t day $^{-1}$, in reasonable agreement with the lidar measurement.

\section{Conclusions}

The $\mathrm{CO}_{2}$ laser-based lidar ATLAS was used to scan the plume of Stromboli volcano. Water vapor concentration and wind speed vector were measured. Eventually, the water vapor flux was retrieved from these two values. The lidar measurement was in agreement with the value obtained with conventional techniques, yet based on completely independent and significantly different approaches. Although the error is rather high, it is the first time that the water vapor flux in a volcanic plume is retrieved by lidar, representing the first direct measurement of this kind ever performed on an active volcano and 
showing the high potential of laser remote sensing in geophysical research.

\section{Acknowledgements}

The authors are deeply grateful to R. Fantoni (ENEA) and S. Gurrieri (INGV-Palermo), for constant encouragement. They extend a special thank-you to N. du Preez and G. Louwrens (SDI Lasers) for useful discussions and laser servicing, respectively, R. Giovagnoli (ENEA) for mechanical parts, D. Del Bugaro (ENEA) and M. Liuzzo (INGV-Palermo) for significant support to field work, and $\mathrm{T}$. Caltabiano (INGV-Catania) for kindly providing $\mathrm{SO}_{2}$ flux data from the FLAME network. D. Poreh gratefully acknowledges the hospitality of ENEA and the support of the Abdus Salam International Centre for Theoretical Physics (ICTP) in the framework of the program Training and Research in Italian Laboratories (TRIL). This research was partially funded by Research Contract V2_01 - Convenzione DPC-INGV 20072009, Project V2: Paroxysm (responsible, A. Aiuppa).

\section{References}

[1] A. Aiuppa, C. Federico, G. Giudice, G. Giuffrida, R. Guida, S. Gurrieri, M. Liuzzo, R Moretti, P. Papale, J. Volcanol. Geoth. Res. 182 (2009) 221.

[2] R.T. Menzies, M.J. Kavaya, P.H. Flamant, D.A. Haner, Appl. Opt. 23 (1984) 2510.

[3] L. Fiorani, F. Colao, A. Palucci, Opt. Lett. 34 (2009) 800.

[4] H. Jaeger, Geophys. Res. Lett. 19 (1992) 191.

[5] J.N. Porter, K.A. Horton, P.J. Mouginis-Mark, B. Lienert, S.K. Sharma, E. Lau, A.J. Sutton, T. Elias, Geophys. Res. Lett. 29 (2002) 1783, doi:10.1029/2002GL014744.

[6] P. Weibring, H. Edner, S. Svanberg, G. Cecchi, L. Pantani, R. Ferrara, T. Caltabiano, Appl. Phys. B 67 (1998) 419.

[7] W.J. Witteman, The $\mathrm{CO}_{2}$ Laser, Springer, Berlin, 1987.

[8] E.W. Eloranta, J.M. King, J.A. Weinman, J. Appl. Meteorol. 14 (1975) 1485.

[9] L. Fiorani, B. Calpini, L. Jaquet, H. Van den Bergh, E. Durieux, Atmos. Environ. 32 (1998) 2151.

[10] L. Fiorani, Lasers and Electro-Optics at the Cutting Edge, Nova, New York, 2007.

[11] J.D. Klett, Appl. Opt. 20 (1981) 211.

[12] F.G. Fernald, Appl. Opt. 23 (1984) 652.

[13] A. Aiuppa, A. Bertagnini, N. Métrich, R. Moretti, M. Liuzzo, G. Tamburello, Earth Planet. Sc. Lett., 295 (2010) 195, doi:10.1016/j.epsl.2010.03.040.

[14] A. Aiuppa, G. Giudice, S. Gurrieri, M. Liuzzo, M. Burton, T. Caltabiano, A.J.S McGonigle, G. Salerno, H. Shinohara, M. Valenza, Geophys. Res. Lett. 35 (2008) L24302, doi:10.1029/2008GL035871.

[15] M. Burton, T. Caltabiano, F. Murè, G. Salerno, D. Randazzo, J. Volcanol. Geoth. Res. 182 (2009) 214. 